\title{
The Auxiliary Subunits Neto1 and Neto2 Reduce Voltage-Dependent Inhibition of Recombinant Kainate Receptors
}

\author{
Janet L. Fisher and David D. Mott \\ Department of Pharmacology, Physiology and Neuroscience, University of South Carolina School of Medicine, Columbia, South Carolina 29208
}

Kainate receptors can be subject to voltage-dependent block by intracellular polyamines, which causes inward rectification of the current-voltage relationship. Sensitivity to polyamine block is largely determined by the identity of a residue within the pore domain that can be altered through RNA editing. This process causes replacement of the encoded glutamine $(\mathrm{Q})$ with a positively charged arginine $(\mathrm{R})$, eliminating polyamine inhibition and thus inward rectification. In neurons, kainate receptors can associate with the auxiliary subunits Neto1 or Neto2. These transmembrane proteins alter the trafficking, channel kinetics, and pharmacology of the receptors in a subunitdependent manner. We found that coexpression of Neto subunits with recombinant GluK2(Q) kainate receptors greatly reduced inward rectification without altering calcium permeability. This effect was separate from modulation of channel kinetics, as mutations within the extracellular LDLa domain of the Neto proteins completely eliminated their effects on desensitization but only reduced their effects on rectification. Conversely, deletion of the intracellular C-terminal domain of Neto1 or Neto2 or neutralization of positively charged residues within this domain prevented the reduction in rectification but did not alter effects on channel kinetics. These results demonstrate new roles for Neto1 and Neto2 in regulating kainate receptor function and identify domains within these auxiliary subunits important for mediating their effects.

\section{Introduction}

Kainate receptors are cation-permeable ionotropic glutamate receptors responsible for regulating excitatory neurotransmission both presynaptically and postsynaptically (Perrais et al., 2010). These tetrameric receptors are assembled from five different subunits (GluK1-GluK5) and the GluK1-3 subunits can form functional homomeric receptors. GluK1 and GluK2 subunits are subject to developmentally regulated RNA editing, causing exchange of an encoded glutamine(Q) for a positively charged arginine(R) residue in the pore domain (Sommer et al., 1991; Bernard and Khrestchatisky, 1994). This structural change has a number of functional effects, including alterations in singlechannel conductance, calcium permeability, and sensitivity to block by intracellular polyamines (Rosenthal and Seeburg, 2012). Polyamines are present in the cytoplasm of most cells at millimolar concentrations, and inhibit GluK1-3(Q)-containing kainate receptors in a voltage-dependent manner (Bowie and Mayer, 1995; Perrais et al., 2009). As a result, the current-voltage relationship for these receptors in whole-cell recordings shows prominent inward rectification, whereas responses in the absence

Received May 1, 2012; revised July 19, 2012; accepted July 23, 2012.

Author contributions: J.L.F. and D.D.M. designed research;J.L.F. and D.D.M. performed research; J.L.F. and D.D.M. analyzed data; J.L.F. and D.D.M. wrote the paper.

This work was supported by NIH-NINDS Grant 1R01NS065869 (to D.D.M. and J.L.F.).

Correspondence should be addressed to Janet L. Fisher, University of South Carolina School of Medicine, Department of Pharmacology, Physiology and Neuroscience, 6439 Garners Ferry Road, Columbia, SC 29209. E-mail: jisher@uscmed.sc.edu.

DOI:10.1523/JNEUROSCI.2211-12.2012

Copyright $\odot 2012$ the authors $\quad 0270-6474 / 12 / 3212928-06 \$ 15.00 / 0$ of polyamines or from receptors containing edited (R) subunits are outwardly rectifying.

Most ionotropic glutamate receptors appear to interact with auxiliary subunits, which are not necessary for channel function, but regulate membrane trafficking, channel kinetics, and pharmacological properties (Jackson and Nicoll, 2011). The TARP (transmembrane AMPAR regulatory proteins) subunits, among others, selectively interact with AMPA receptors, while in hippocampal and cerebellar neurons, postsynaptic kainate receptors were shown to coassemble with the auxiliary proteins Netol or Neto2 (Zhang et al., 2009; Tang et al., 2011). Interestingly, although the TARP and Neto proteins are structurally unrelated, they share some functional effects. Subtypes within both groups can slow the kinetics of desensitization and deactivation, change agonist profiles, and may alter surface expression and trafficking (Jackson and Nicoll, 2011). In addition, the TARP subunit stargazin $(\gamma-2)$ reduces inhibition of AMPA receptors by intracellular polyamines, and therefore reduces inward rectification (Soto et al., 2007). To determine whether this function is also shared by the Neto proteins, we examined the effect of Netol or Neto 2 on the voltage-dependent properties of recombinant, homomeric GluK2(Q) receptors.

\section{Materials and Methods}

Mammalian expression vectors encoding full-length cDNA for rat GluK2(Q) (in JG3.6, provided by S. Heinemann, Salk Institute, San Diego, CA), human Neto1 (in pCAGGS) and rat Neto2 (in pCDNA3, both Neto1 and Neto 2 provided by S. Tomita, Yale University, New Haven, CT) were transiently transfected into HEK-293T (GenHunter) cells using calcium phosphate precipitation, as previously described (Mott et al., 

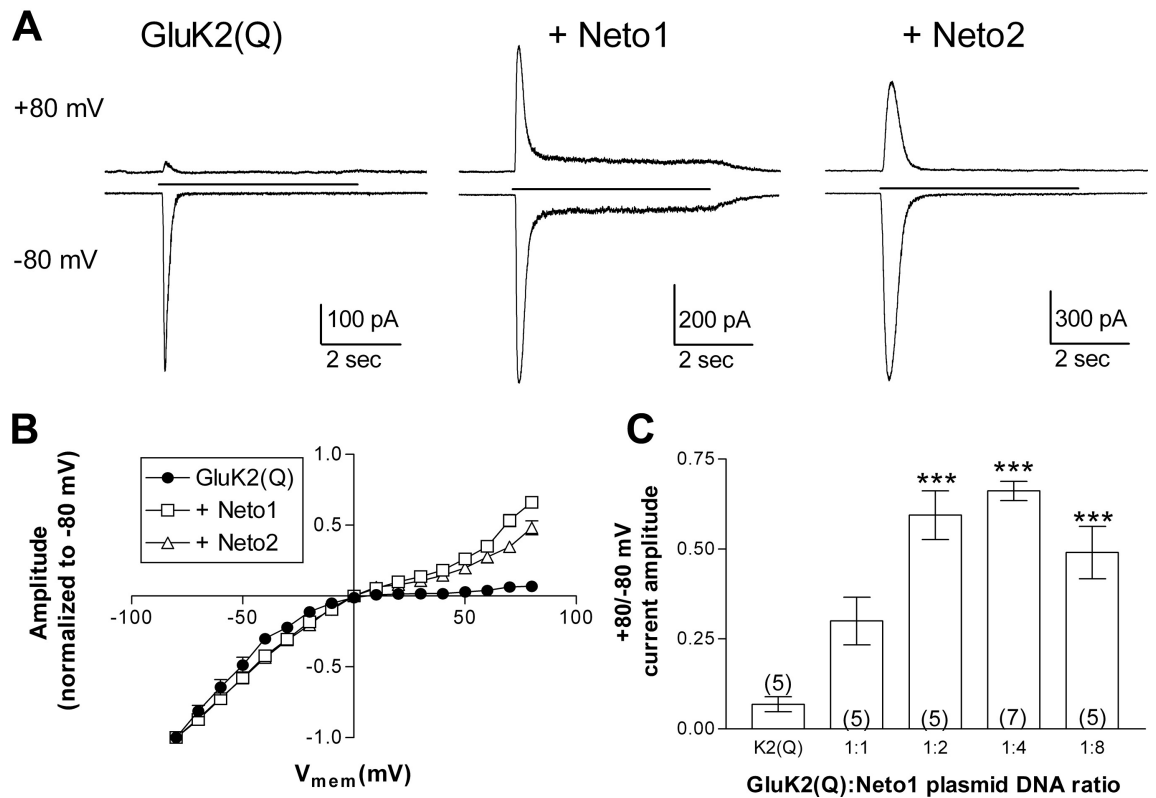

Figure 1. Coexpression with Net01 or Net02 reduces inward rectification of GluK2(Q) receptors. $A$, Whole-cell current traces from HEK-293T cells transiently transfected with GluK2(Q) alone, or GluK2(Q) with either Net01 or Neto2. Plasmids were transfected in a 1:4 (GluK2:Neto) ratio with $1 \mu \mathrm{g}$ of GluK2 plasmid DNA. Glutamate (100 $\mu \mathrm{M}$ ) was applied for $5 \mathrm{~s}$ (horizontal bar) to cells voltage clamped at +80 or $-80 \mathrm{mV}$, as indicated. $\boldsymbol{B}$, Current-voltage relationships for cells transfected with GluK2(Q) alone or with Net01 or Net02. Transfection conditions as in $\boldsymbol{A}$. The peak current amplitude was normalized to the response at $-80 \mathrm{mV}$ for each cell. $N=5$ cells for each subunit combination. $C$, GluK2(Q)-encoding plasmid DNA (1 $\mu \mathrm{g})$ was cotransfected with varying amounts of Net01-containing plasmid. The peak current at $+80 \mathrm{mV}$ was divided by that at $-80 \mathrm{mV}$. Error bars indicate mean \pm SEM with the $n$ given by the number in parentheses. ***Significant difference from GluK2(Q) $(p \leq 0.001)$.

2010). Unless otherwise noted, cells were transfected with $1 \mu \mathrm{g}$ of GluK2 and $4 \mu \mathrm{g}$ of Netol/2 plasmid DNA.

For whole-cell recordings, the external bath solution contained the following (in mM): $150 \mathrm{NaCl}, 3 \mathrm{KCl}, 10 \mathrm{HEPES}, 1 \mathrm{CaCl}_{2}$, and $0.4 \mathrm{MgCl}_{2}$ adjusted to $\mathrm{pH} 7.4$ and $295-305 \mathrm{mOsm}$. Patch pipettes were pulled from borosilicate glass with an internal filament (World Precision Instruments) on a two-stage puller (Narishige) to 5-10 $\mathrm{M} \Omega$ and filled with a solution containing the following (in $\mathrm{mm}$ ): $130 \mathrm{CsGluconate,} 5 \mathrm{CsCl}, 10$ HEPES, 5 CsBAPTA, $2 \mathrm{MgCl}_{2}$, 2 MgATP, and $0.3 \mathrm{NaGTP}$ with pH 7.3 and osmolarity 290-300 mOsm. Polyamines were not added to the internal solution. The $+80 /-80$ amplitude ratio did not change over the course of the 20-30 min recording period, suggesting limited washout of endogenous polyamines. For measurement of $\mathrm{Na}^{+} / \mathrm{Ca}^{2+}$ permeability, the intracellular solution contained the following (in $\mathrm{mm}$ ): $140 \mathrm{CsCl}, 1$ $\mathrm{MgCl}_{2}, 10$ EGTA, and $10 \mathrm{HEPES}$ (pH 7.2 with $\mathrm{CsOH}$ ). High $\mathrm{Na}^{+}$extracellular solution contained the following (in $\mathrm{mm}$ ): $140 \mathrm{NaCl}$ and 10 HEPES (pH 7.2 with $\mathrm{NaOH}$ ). High $\mathrm{Ca}^{2+}$ extracellular solution contained the following (in mM): $110 \mathrm{CaCl}_{2}$ and 10 HEPES (pH 7.2 with $\mathrm{CaOH}_{2}$ ).

Agonists were diluted into external solution and applied to cells using a computer-controlled exchanger with an exchange time of 20-30 ms (SF77B; Warner Instruments). Current recordings were amplified (Axopatch 200B; Molecular Devices), filtered ( $1 \mathrm{kHz})$, and digitized at $10 \mathrm{kHz}$ using a Digidata 1320 analog to digital board (Molecular Devices).

Whole-cell currents were analyzed using Clampfit (pClamp9.2 or 10 suite; Molecular Devices), Prism (Graphpad), and Origin7.5 (Origin$\mathrm{Lab}$ ). The onset of desensitization was fit with a single exponential function using Levenberg-Marquardt least-squares method. ANOVA and Tukey-Kramer multiple-comparisons tests were performed with Instat (Graphpad) using a significance level of $p<0.05$.

\section{Results}

Neto1 and Neto2 reduce inward rectification of GluK2(Q) kainate receptors

Homomeric kainate receptors containing the unedited (Q) form of the GluK2 subunit respond to $100 \mu \mathrm{M}$ glutamate with rapid and complete desensitization and show strong inward rectification in whole-cell recordings (Fig. 1). We found that addition of either Neto1 or Neto 2 altered both the desensitization kinetics and the amount of inward rectification (Fig. $1 A, B)$. At this glutamate concentration, the effects of each Neto subunit were clearly distinct. The greatest impact of Neto1 was on the extent of desensitization. GluK2(Q) receptors produced no measurable current by the end of a $5 \mathrm{~s}$ application of $100 \mu \mathrm{M}$ glutamate, but with Netol the steady-state current averaged $11.0 \pm 1.0 \%(n=7)$ of the peak current. In contrast, Neto 2 primarily slowed the onset of desensitization (Fig. 1A). Although the whole-cell recording configuration did not permit accurate measurement of the fast components of desensitization, cotransfection with Neto2 clearly altered desensitization, slowing the average decay time constant from $100 \pm 10$ $\mathrm{ms}(n=5)$ to $360 \pm 30 \mathrm{~ms}(n=6)$.

While Neto1 and Neto2 had distinct effects on the receptor's kinetic properties, both significantly reduced inward rectification. Because of voltage-dependent block by intracellular polyamines, little outward current was observed at positive membrane potentials in the absence of Neto and the $+80 \mathrm{mV} /-80$ amplitude ratio averaged $0.07 \pm 0.02$. However, in the presence of either Neto1 or Neto2, the current-voltage relationship became more linear (with $+80 /-80$ ratios averaging $0.66 \pm 0.03$ and $0.48 \pm 0.05$, respectively), without a change in the reversal potential (Fig. $1 A, B$ ). The effectiveness of Netol depended on the relative amount of plasmid DNA transfected. Previous studies used kainate receptor subunit:Neto ratios ranging from 1:3 to 1:30 (Zhang et al., 2009; Straub et al., 2011a). We varied the amount of Netol plasmid DNA cotransfected with 1 $\mu \mathrm{g}$ of DNA encoding GluK2(Q) and measured the current at +80 and $-80 \mathrm{mV}$ (Fig. 1C). A ratio of 1:4 appeared to be optimal under our conditions, with the greatest effect on rectification and reduced variability compared with a ratio of $1: 2$. We therefore used this DNA ratio for Neto1 and Neto2 in all further experiments.

\section{Neto 1 and Neto2 do not alter calcium permeability}

In addition to effects on polyamine block and inward rectification, the $\mathrm{Q} / \mathrm{R}$ modification also impacts ionic selectivity, with GluK2(Q)-containing receptors having significantly greater calcium permeability (Burnashev et al., 1995). To determine whether the Neto subunits influence this property, we examined the relative $\mathrm{Na}^{+}: \mathrm{Ca}^{2+}$ permeability of GluK2(Q) receptors. To maintain a steady-state current for the duration of the voltage ramp, we used the weakly desensitizing agonist domoate. Starting at $5 \mathrm{~s}$ into the domoate application, when the current had reached steady state, the holding voltage was ramped from $-100 \mathrm{mV}$ to $+70 \mathrm{mV}$ over a period of $2 \mathrm{~s}$ (Fig. 2).

For GluK2(Q) receptors, the reversal potential in high $\mathrm{Ca}^{2+}$ extracellular solution shifted by $-27.2 \pm 4.2 \mathrm{mV}(n=7)$, similar to previous reports (Köhler et al., 1993; Burnashev et al., 1995). The addition of Neto 1 or Neto 2 did not alter this shift in reversal 
A

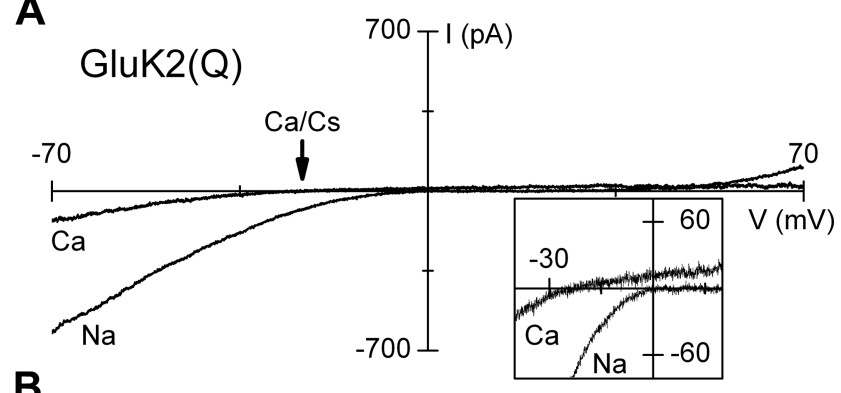

B

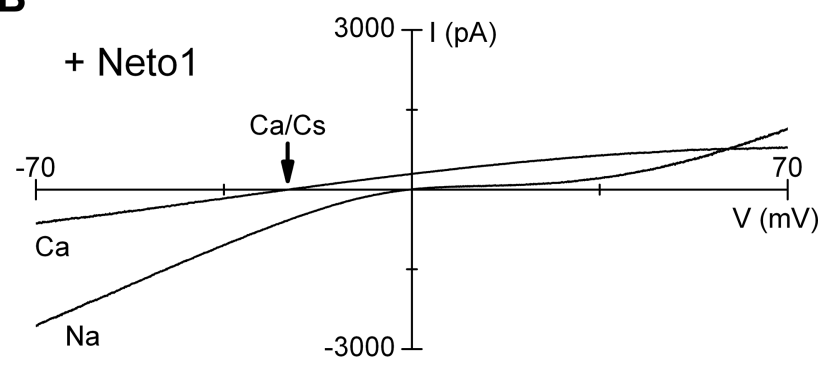

C

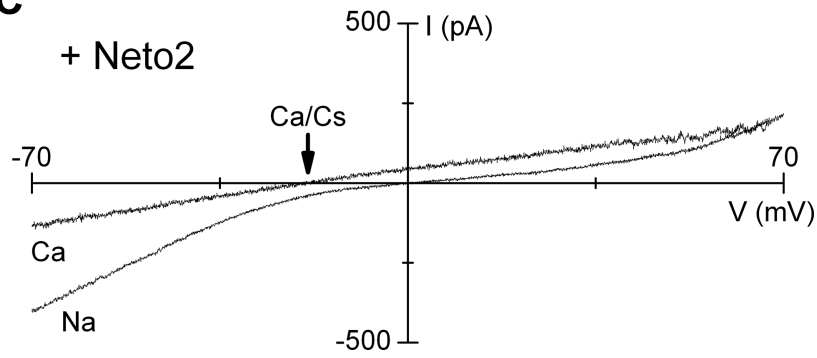

Figure 2. Effect of Neto subunits on $\mathrm{Ca}^{2+}$ permeability. $\mathbf{A}-\mathbf{C}$, Steady-state current voltage relationships in response to $10 \mu \mathrm{m}$ domoate in either high $\mathrm{Na}^{+}$or high $\mathrm{Ca}^{2+}$ external solution for GluK2(Q) alone $(\boldsymbol{A})$, with Neto1 (B), or with Neto2 (C). The inset shows GluK2(Q) reversal potentials at higher resolution. Voltage ramps in the presence and absence of domoate were subtracted to determine the reversal potential in each solution. The measured shift in reversal potential between $\mathrm{Na}^{+} / \mathrm{Cs}^{+}$and $\mathrm{Ca}^{2+} / \mathrm{Cs}^{+}$was corrected by the junction potential $(9.3 \mathrm{mV})$. In high $\mathrm{Na}^{+}$, the average reversal potential was close to $0 \mathrm{mV}$ and was corrected to 0 in all experiments, with an equal correction applied to the $\mathrm{Ca}^{2+} / \mathrm{Cs}^{+}$reversal potential. Arrows indicate the $\mathrm{Ca}^{2+} / \mathrm{Cs}^{+}$reversal potentials that were $-27 \mathrm{mV}$ (GluK2), $-24 \mathrm{mV}$ (+ Neto1), and $-26 \mathrm{mV}(+$ Neto2).

potential $\left(V_{\text {rev }}\right)$ in high $\mathrm{Ca}^{2+}$ (Netol: $V_{\text {rev }}=-24.4 \pm 0.8 \mathrm{mV}$, $n=5$; Neto2: $V_{\text {rev }}=-26.2 \pm 5.7 \mathrm{mV}, n=6$; Fig. 2$)$, indicating that these proteins do not alter the $\mathrm{Ca}^{2+}$ permeability. This lack of effect on calcium permeability is similar to that of $\operatorname{stargazin}(\gamma$ 2 ), which also reduces inward rectification of AMPA receptors without affecting ion selectivity (Soto et al., 2007).

\section{Mutations within the LDL-receptor class A repeat domain} eliminate Neto effects on kinetics, but not on rectification Little is known about the structural domains within the Neto proteins that confer their functional effects. It is possible that the same mechanisms that produce the changes in desensitization kinetics are also responsible for decreasing inward rectification, as conformational changes in the channel could alter both kinetics and access to a blocking site. For example, in addition to reducing block by intracellular polyamines, some TARP subunits also enhance block of AMPA receptors by extracellular polyamines (Jackson et al., 2011). This activity was correlated to an increase in channel conductance and was agonist-dependent, suggesting that both resulted from a change in pore structure.
To determine whether the effects of the Neto proteins on desensitization kinetics could be dissociated from those on inward rectification, we created point mutations at two cysteine residues within the LDL-receptor class A repeat (LDLa) domains of Neto1 and Neto2 (Fig. 3A). Previous work showed that these residues are necessary for Neto 2 to enhance the glutamate-induced current in oocyte recordings (Zhang et al., 2009). We created mutated $\mathrm{Neto}_{(\mathrm{C} 270 \mathrm{~S} / \mathrm{C} 304 \mathrm{~S})}$ and $\mathrm{Neto} 2_{(\mathrm{C} 271 \mathrm{~S} / \mathrm{C} 305 \mathrm{~S})}$ subunits and coexpressed them with wild-type GluK2(Q) (Fig. 3B). In both cases, these mutations largely eliminated the effects of the Neto proteins on desensitization. For the $\mathrm{Neto1}_{(\mathrm{C} 270 \mathrm{~S} / \mathrm{C} 304 \mathrm{~S})}$ subunit, the steady-state current remaining at the end of the $5 \mathrm{~s}$ application was decreased to $0.79 \pm 0.18 \%$ of the peak current $(n=$ $6, p \leq 0.001$ compared with wild-type Neto1). With the Neto2 (C271S/C305s) mutations, the rate of onset of desensitization was similar to that of GluK2(Q) alone $(p>0.05)$ and significantly different from wild-type Neto2 $(n=6, p \leq 0.001$; Fig. $3 E$ ). However, despite the loss of these kinetic effects, both $\mathrm{Neto}_{(\mathrm{C} 270 \mathrm{~S} / \mathrm{C} 304 \mathrm{~S})}$ and Neto2 (C271S/C305S) still significantly reduced the amount of rectification compared with GluK2(Q) alone (Fig. $3 B, D$ ).

The intracellular domains of Neto 1 and Neto 2 are responsible for their effects on inward rectification

While the LDLa domain mutations clearly had a larger impact on modulation of channel kinetics than on inward rectification, the ability to alter rectification was also significantly reduced. This might reflect a decrease in surface expression of the auxiliary subunits coassembled with the kainate receptor, as previously observed with these mutations in Neto2 (Zhang et al., 2009). However, others found that deletion of the LDLa domain in Neto2 did not reduce its interaction with GluK2 (Tang et al., 2011). Alternatively, this result could indicate that the two functional effects are correlated, possibly sharing a structural mechanism. To further address this question, we sought to identify structures responsible for the effect on rectification. We focused on the intracellular C-terminal domain of the Neto subunits, as this region might directly interact with the cytoplasmic polyamines. For both Neto proteins, these domains contain a substantial number of charged residues. The C-terminal domain of Neto1 is 168 aa in length, 47 of which are charged, while this domain in Neto 2 contains 155 aa, with 44 charged residues. Earlier studies showed that deletion of the intracellular domain of Neto subunits did not impair their association with kainate receptor subunits (Tang et al., 2011).

To determine whether the intracellular domain could be responsible for reducing inward rectification, we inserted a stop codon near the putative transmembrane domain of Neto (Stöhr et al., 2002), truncating the protein after R347 in Neto1(c-del) or R348 in Neto2(c-del). These truncated constructs were coexpressed with GluK2(Q) and the response to $100 \mu \mathrm{M}$ glutamate measured at -80 and $+80 \mathrm{mV}$ (Fig. $3 C, D$ ). Deletion of the C-terminal domain had no effect on the ability of the Neto proteins to modify the kinetic properties of the receptor, as Neto2(cdel) slowed the onset of desensitization to the same extent as wild-type Neto2 (Fig. 3C,E) and Neto1(c-del) produced a similar increase in the steady-state current (averaging $9.7 \pm 2.1 \%$ of the peak current). However, for both Netol and Neto2, the reduction of inward rectification was completely eliminated by removal of the C-terminal domain (Fig. 3C,D). 


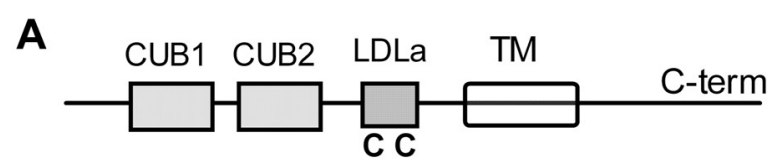

B LDLa Cys-Ser mutations

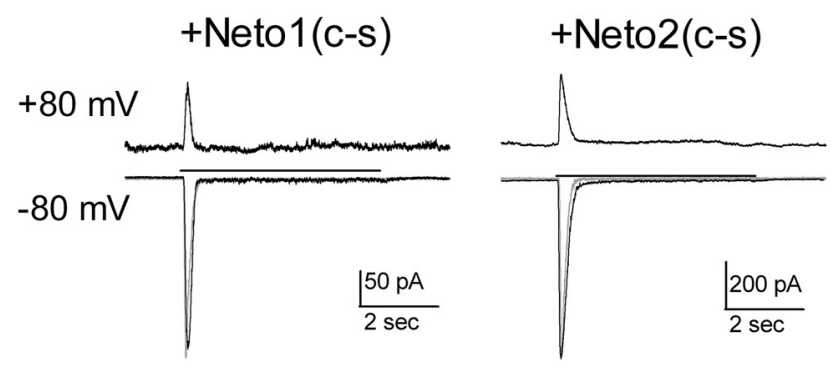

C C-terminal deletions

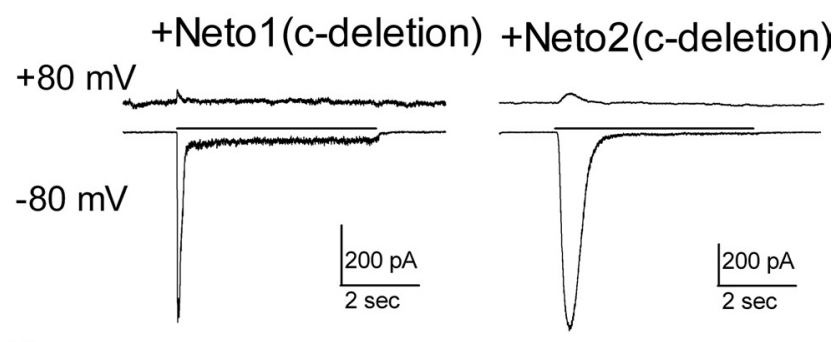

D

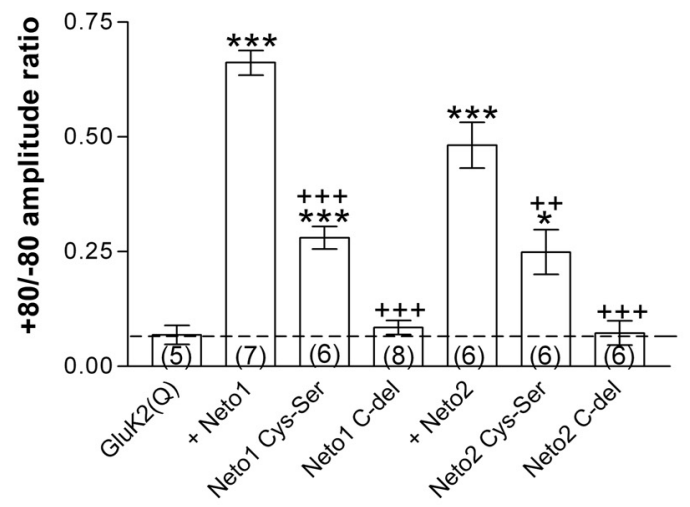

E

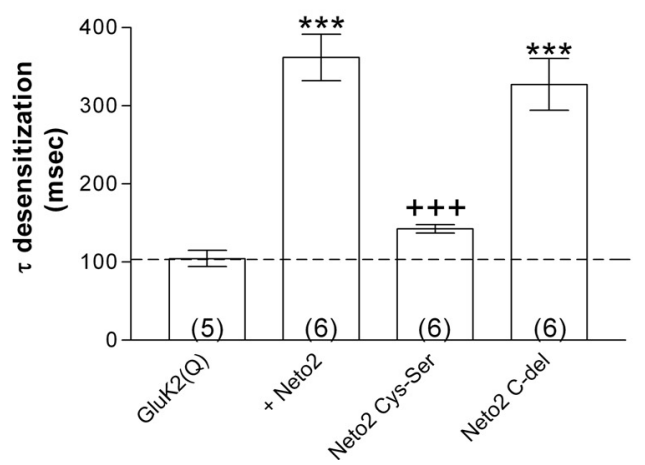

Figure 3. Effects of Net01/2 on channel kinetics and rectification are mediated by distinct structures. $\boldsymbol{A}$, Schematic representation of the Neto subunit structure. The extracellular $\mathrm{N}$-terminal sequence contains two CUB domains and one region with homology to the LDLa (Stöhr et al., 2002). This domain contains two cysteine residues ( $\boldsymbol{C}$ ) required for Net02 to effectively enhance kainate receptor activity (Zhang et al., 2009). The single transmembrane domain (TM) is followed by an intracellular C-terminal domain. $\boldsymbol{B}$, Two cysteine residues within the LDLa domain of Net01 or Neto2 were mutated to serine. GluK2(Q) receptors were coexpressed with
Role of charged residues within the C-terminal domain

These results demonstrate that the distinct effects of the Neto proteins on channel kinetics and inward rectification can be functionally and structurally separated, and that the intracellular C-terminal domain plays a critical role only for the latter effect. To identify the responsible sites within this domain, we created a series of progressive truncations of the Neto2 subunit (Fig. $4 A, B)$. From the full-length domain of 155 aa, terminating at Phe499, we inserted stop codons to produce C-terminal domains terminating at Arg407 (63 residues), Leu377 (33 residues), or Asn359 (15 residues) (Fig. 4A,B). We found that even a Neto2 containing only 15 residues of the original $\mathrm{C}$-terminal domain reduced inward rectification to the same extent as the full-length protein (Fig. $4 A, B$ ).

These findings implicated the region between R347 and N359 in the Neto2 intracellular domain. Within this sequence, Neto2 contains four positively charged residues. These four residues are conserved in Neto1, which also includes an additional arginine residue (Fig. 4C). To determine whether these residues are necessary for the effect of the Neto proteins, we mutated each of them to alanine (Fig. $4 D-F$ ). Individual mutations of single residues in Neto2 had no impact on its function (Fig. 4D). However, mutation of both R353 and K354 to alanine in the Netol subunit significantly reduced its effectiveness, and triple mutations of the RKK sequence within either Neto1 or Neto2 completely prevented their activity (Fig. $4 E, F$ ). Although the single mutations had no effect on the amount of rectification produced by endogenous levels of polyamines in the whole-cell recording configuring, excised patches could be used to determine whether each individual residue influences the concentration dependence of block. The triple mutations did not alter the impact of either $\mathrm{Neto}_{(\mathrm{R} 347 \mathrm{~A} / \mathrm{K} 348 \mathrm{~A} / \mathrm{K} 349 \mathrm{~A})}$ or Neto2 ${ }_{(\mathrm{R} 348 \mathrm{~A} / \mathrm{K} 349 \mathrm{~A} / \mathrm{K} 350 \mathrm{~A})}$ on receptor desensitization, with the extent of desensitization (Netol: $10.9 \pm 1.5 \%, n=5$ ) or onset of desensitization (Neto2: $370 \pm$ $40 \mathrm{~ms}, n=5$ ) similar to that produced by the respective wildtype Neto subunits.

\section{Discussion}

We found that the auxiliary subunits Neto 1 and Neto2 influenced both rectification and desensitization of recombinant GluK2(Q) kainate receptors. The effects on channel kinetics were generally consistent with previous studies, which reported that both Neto1 and Neto 2 altered the onset and recovery from desensitization of kainate receptors in a subunit-dependent manner (Zhang et al., 2009; Copits et al., 2011; Straub et al., 2011a,b). In contrast, the

\footnotetext{
$\leftarrow$

these mutated constructs; black traces show representative responses to $5 \mathrm{~s}$ applications of 100 $\mu \mathrm{m}$ glutamate (horizontal line) at membrane potentials of +80 or $-80 \mathrm{mV}$. The underlying gray trace shows the response at $-80 \mathrm{mV}$ of GluK2(0) receptors without Neto (same trace as Fig. 1A). C, The C-terminal domain of Net01 or Net02 was truncated after the fourth amino acid residue; these constructs were coexpressed with $\mathrm{GluK2}(\mathrm{Q})$. Current traces are in response to $5 \mathrm{~s}$ applications of $100 \mu \mathrm{m}$ glutamate at +80 or $-80 \mathrm{mV}$. D, The rectification ratio was calculated by dividing the amplitude of the peak response at $+80 \mathrm{mV}$ by that at $-80 \mathrm{mV}$. The reversal potential was not affected by any of the mutations and was near $0 \mathrm{mV}$ in all cases. Significant difference from GluK2(Q) receptors: ${ }^{* *} p \leq 0.001,{ }^{*} p \leq 0.05$; significant difference from the corresponding wild-type Neto protein: ${ }^{++} p \leq 0.001,{ }^{++} p \leq 0.01$. Error bars represent mean \pm SEM and the number of cells is indicated by the number in parentheses. The dashed line shows the mean response of $G$ luK2 $(Q)$ receptors in the absence of Neto. $\boldsymbol{E}$, The onset of desensitization was measured by fitting the decay of whole-cell currents with a single exponential. Error bars represent mean \pm SEM with the number of cells indicated by the number in parentheses. The dashed line shows the mean response of GluK2(Q) receptors in the absence of Neto. ${ }^{* *}$ Significant difference from GluK2 $(Q)$ receptors $(p \leq 0.001) ;{ }^{++}+$Significant difference from wild-type Net02 ( $p \leq 0.001)$
} 
A Neto2

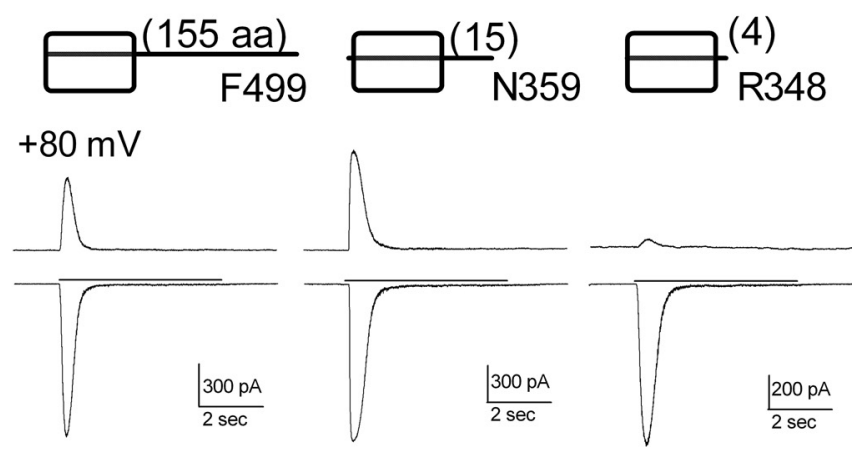

$-80 \mathrm{mV}$

C

Neto $2 \ldots K_{345}$ QPRKKVMACKTAFN $359 \ldots$

Neto $1 \ldots K_{344} Q P R K K Y V Q R K S D F D_{358} \ldots$

E

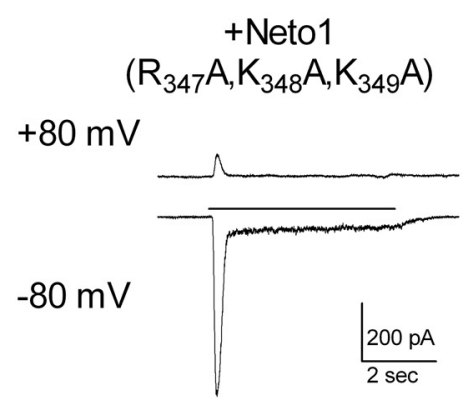

\section{B Neto2 truncations}

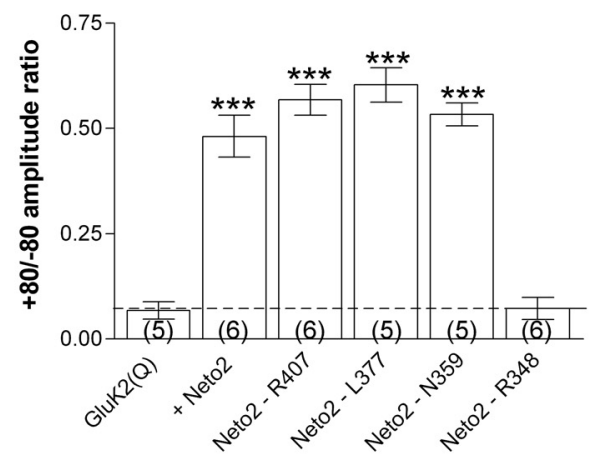

D Neto2 single point mutations

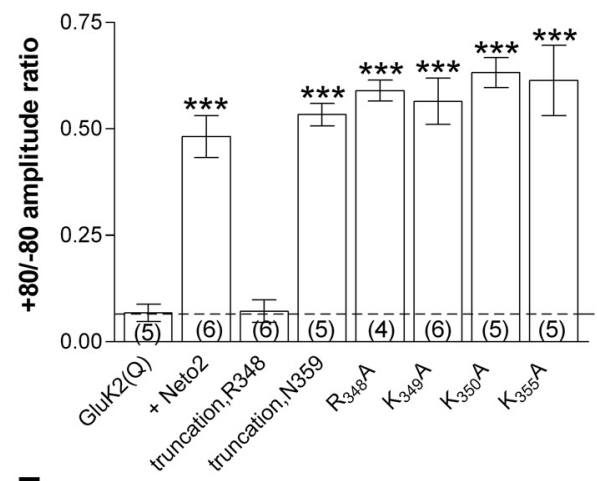

$\mathbf{F}$

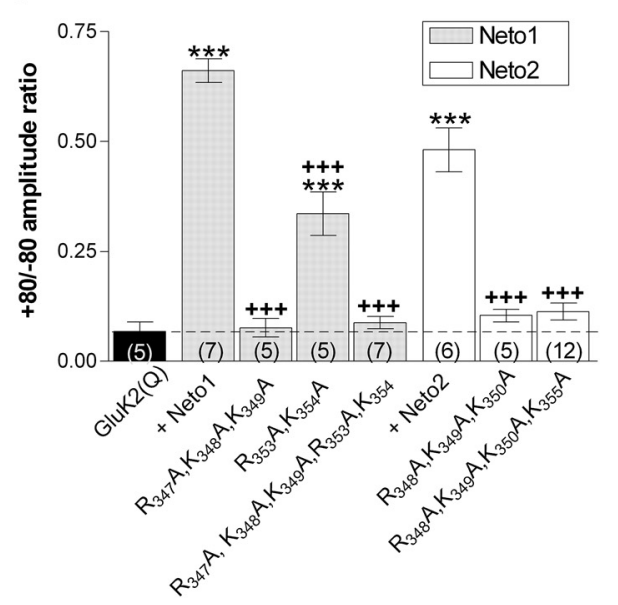

Figure 4. A series of positively charged residues near the transmembrane domain of Neto1/2 mediate their effects on GluK2(Q) rectification. $A$, The intracellular C-terminal domain of Neto2 was progressively truncated to determine the minimum length necessary to reduce inward rectification of GluK2(Q). Schematics represent the wild-type subunit and two of the truncated subunits, showing the number of residues and the terminating amino acid for each construct. Representative current traces in response to $100 \mu \mathrm{m}$ glutamate at +80 or $-80 \mathrm{mV}$ for receptors containing the indicated Neto2 subunit with GluK2(Q). $\boldsymbol{B}$, The ratio of the response at +80 and $-80 \mathrm{mV}$ is shown as mean $\pm \mathrm{SEM}$, with the number of cells indicated by the number in parentheses. The Neto2 truncation constructs are named by their terminating residues. The dashed line shows the mean response for GluK2 $(Q)$ alone. ${ }^{* *}$ Significant difference from GluK2 $(Q)$ in the absence of Neto2 ( $p \leq$ 0.001). C, Amino acid sequences for Neto 1 and Neto2 are aligned from the start of the intracellular domain through the site of the shortest truncation in Neto 2 that permitted full function. Positively charged residues located in the functionally critical region between Arg348 and Asn359 of Neto2 are indicated in bold type. $\boldsymbol{D}$, Positively charged residues in Neto2 were individually mutated to alanine. Graph is constructed as described in $\boldsymbol{B}$. $\boldsymbol{E}$, Triple mutations were made in the intracellular domain of Neto 1 or Net02, converting the conserved RKK sequence in each subunit to AAA. Current traces show the response to $100 \mu \mathrm{m}$ glutamate. $\boldsymbol{F}$, Multiple arginine or lysine residues in Neto1 or Net02 were mutated to alanine. Graph is constructed as described in $\boldsymbol{B}$. ${ }^{* *}$ Significant difference from GluK2(Q) receptors $(p \leq 0.001) ;{ }^{+++}$Significant difference from wild-type Net01 or Neto2 $(p \leq 0.001)$.

present study is the first to describe a role for the Neto subunits in reducing inward rectification of kainate receptors. In addition to its modulation of kainate receptors, Neto1 also interacts with NMDA receptors, regulating their expression at synapses and playing an im- portant role in synaptic plasticity (Ng et al., 2009). Since NMDA receptors are not regulated by cytoplasmic polyamines (Williams, 1997), it may be interesting to determine whether the C-terminal domain of Neto1 has a different role with these receptors. 
Our results suggest that a series of three adjacent positively charged residues located near the intracellular side of the transmembrane domain in Neto1 and Neto2 are responsible for the decrease in inward rectification. These residues may act as a charge screen, reducing access of the positively charged polyamines to the pore of the channel. However, other possible mechanisms can also be imagined. For example, in the absence of Neto proteins, polyamine interaction with the kainate subunits is influenced not just by $\mathrm{Q} / \mathrm{R}$ editing, but also by a nearby negatively charged residue, which is necessary for high affinity binding (Panchenko et al., 1999). The RKK sequence of the Neto proteins that we identified could neutralize the impact of this residue and thus reduce rectification. Hydrophobic residues surrounding the channel pore also influence block and contribute to the exceptionally high polyamine affinity associated with the GluK3 subunit (Panchenko et al., 2001; Perrais et al., 2009). In addition, extracellular structures have been found to regulate polyamine sensitivity, presumably by altering pore structure (Perrais et al., 2009). The Neto subunits could influence inward rectification through any of these mechanisms, although our results demonstrate a critical role for positively charged intracellular residues located near the membrane.

In addition to their voltage-dependent inhibition of outward current, polyamines also produce tonic inhibition of ionotropic glutamate receptors by binding to the channel's closed state. This tonic inhibition can be relieved by ion flow through the channel, producing an activity-dependent facilitation of glutamatergic synapses (Rozov et al., 1998; Rozov and Burnashev, 1999). The amount of facilitation could be influenced by both polyamines and by coassembly with auxiliary subunits (Soto et al., 2007). Polyamine levels are regulated during development (Shin et al., 2005) and can change in response to neuronal activity (Aizenman et al., 2002). Together, these studies suggest that the effects of Neto proteins on kainate receptor function could vary as a function of both development and behavioral state.

\section{References}

Aizenman CD, Muñoz-Elías G, Cline HT (2002) Visually driven modulation of glutamatergic synaptic transmission is mediated by the regulation of intracellular polyamines. Neuron 34:623-634.

Bernard A, Khrestchatisky M (1994) Assessing the extent of RNA editing in the TMII regions of GluR5 and GluR6 kainate receptors during rat brain development. J Neurochem 62:2057-2060.

Bowie D, Mayer ML (1995) Inward rectification of both AMPA and kainate subtype glutamate receptors generated by polyamine-mediated ion channel block. Neuron 15:453-462.

Burnashev N, Zhou Z, Neher E, Sakmann B (1995) Fractional calcium currents through recombinant GluR channels of the NMDA, AMPA and kainate receptor subtypes. J Physiol 485:403-418.

Copits BA, Robbins JS, Frausto S, Swanson GT (2011) Synaptic targeting and functional modulation of GluK1 kainate receptors by the auxiliary neuropilin and tolloid-like (NETO) proteins. J Neurosci 31:7334-7340.

Jackson AC, Nicoll RA (2011) The expanding social network of ionotropic glutamate receptors: TARPs and other transmembrane auxiliary subunits. Neuron 70:178-199.
Jackson AC, Milstein AD, Soto D, Farrant M, Cull-Candy SG, Nicoll RA (2011) Probing TARP modulation of AMPA receptor conductance with polyamine toxins. J Neurosci 31:7511-7520.

Köhler M, Burnashev N, Sakmann B, Seeburg PH (1993) Determinants of $\mathrm{Ca}^{2+}$ permeability in both TM1 and TM2 of high affinity kainate receptor channels: diversity by RNA editing. Neuron 10:491-500.

Mott DD, Rojas A, Fisher JL, Dingledine RJ, Benveniste M (2010) Subunitspecific desensitization of heteromeric kainate receptors. J Physiol 588:683-700.

Ng D, Pitcher GM, Szilard RK, Sertié A, Kanisek M, Clapcote SJ, Lipina T, Kalia LV, Joo D, McKerlie C, Cortez M, Roder JC, Salter MW, McInnes RR (2009) Netol is a novel CUB-domain NMDA receptor-interacting protein required for synaptic plasticity and learning. PLoS Biology 7:e41.

Panchenko VA, Glasser CR, Partin KM, Mayer ML (1999) Amino acid substitutions in the pore of rat glutamate receptors at sites influence block by polyamines. J Physiol 520:337-357.

Panchenko VA, Glasser CR, Mayer ML (2001) Structural similarities between glutamate receptor channels and $\mathrm{K}^{+}$channels examined by scanning mutagenesis. J Gen Physiol 117:345-360.

Perrais D, Coussen F, Mulle C (2009) Atypical functional properties of GluK3-containing kainate receptors. J Neurosci 29:15499-15510.

Perrais D, Veran J, Mulle C (2010) Gating and permeation of kainate receptors: differences unveiled. Trends Pharmacol Sci 31:516-522.

Rosenthal JJ, Seeburg PH (2012) A-to-I RNA editing: effects on proteins key to neural excitability. Neuron 74:432-439.

Rozov A, Burnashev N (1999) Polyamine-dependent facilitation of postsynaptic AMPA receptors counteracts paired-pulse depression. Nature 401:594-598.

Rozov A, Zilberter Y, Wollmuth LP, Burnashev N (1998) Facilitation of currents through rat $\mathrm{Ca}^{2+}$-permeable AMPA receptor channels by activity-dependent relief from polyamine block. J Physiol 511:361-377.

Shin J, Shen F, Huguenard JR (2005) Polyamines modulate AMPA receptor-dependent synaptic responses in immature layer $\mathrm{V}$ pyramidal neurons. J Neurophysiol 93:2634-2643.

Sommer B, Köhler M, Sprengel R, Seeburg PH (1991) RNA editing in the brain controls a determinant of ion flow in glutamate-gated channels. Cell 67:11-19.

Soto D, Coombs ID, Kelly L, Farrant M, Cull-Candy SG (2007) Stargazin attenuates intracellular polyamine block of calcium-permeable AMPA receptors. Nat Neurosci 10:1260-1267.

Stöhr H, Berger C, Fröhlich S, Weber BH (2002) A novel gene encoding a putative transmembrane protein with two extracellular CUB domains and a low-density lipoprotein class A module: isolation of alternatively spliced isoforms in retina and brain. Gene 286:223-231.

Straub C, Zhang W, Howe JR (2011a) Neto2 modulation of kainate receptors with different subunit compositions. J Neurosci 31:8078-8082.

Straub C, Hunt DL, Yamasaki M, Kim KS, Watanabe M, Castillo PE, Tomita S (2011b) Distinct functions of kainate receptors in the brain are determined by the auxiliary subunit Neto 1. Nat Neurosci 14:866-873.

Tang M, Pelkey KA, Ng D, Ivakine E, McBain CJ, Salter MW, McInnes RR (2011) Netol is an auxiliary subunit of native synaptic kainate receptors. J Neurosci 31:10009-10018.

Williams K (1997) Interactions of polyamines with ion channels. Biochem J 325:289-297.

Zhang W, St-Gelais F, Grabner CP, Trinidad JC, Sumioka A, MorimotoTomita M, Kim KS, Straub C, Burlingame AL, Howe JR, Tomita S (2009) A transmembrane accessory subunit that modulates kainate-type glutamate receptors. Neuron 61:385-396. 